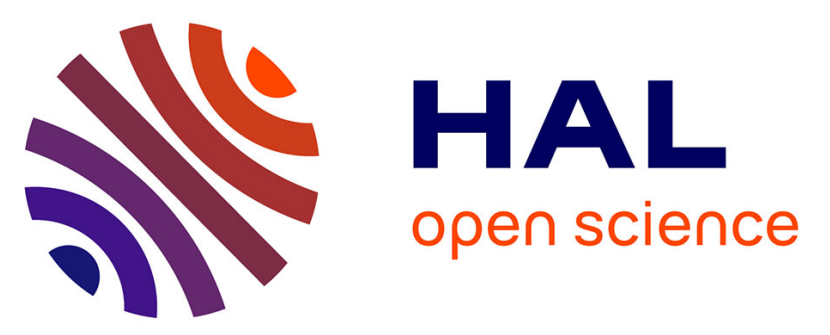

\title{
Cyanine derivative as a suitable marker for thermosensitive in situ gelling delivery systems: In vitro and in vivo validation of a sustained buccal drug delivery
}

Ni Zeng, Johanne Seguin, Pierre-Louis Destruel, Gilles Dumortier, Marc Maury, Hélène Dhotel, Michel Bessodes, Daniel Scherman, Nathalie Mignet, Vincent Boudy

\section{To cite this version:}

Ni Zeng, Johanne Seguin, Pierre-Louis Destruel, Gilles Dumortier, Marc Maury, et al.. Cyanine derivative as a suitable marker for thermosensitive in situ gelling delivery systems: In vitro and in vivo validation of a sustained buccal drug delivery. International Journal of Pharmaceutics, 2017, 534 (1-2), pp.128-135. 10.1016/j.ijpharm.2017.09.073 . hal-02123148

\section{HAL Id: hal-02123148 \\ https://hal.science/hal-02123148}

Submitted on 8 May 2019

HAL is a multi-disciplinary open access archive for the deposit and dissemination of scientific research documents, whether they are published or not. The documents may come from teaching and research institutions in France or abroad, or from public or private research centers.
L'archive ouverte pluridisciplinaire HAL, est destinée au dépôt et à la diffusion de documents scientifiques de niveau recherche, publiés ou non, émanant des établissements d'enseignement et de recherche français ou étrangers, des laboratoires publics ou privés. 


\title{
Cyanine derivative as a suitable marker for thermosensitive in situ gelling delivery systems: in vitro and in vivo validation of a sustained buccal drug delivery
}

Ni Zeng ${ }^{\text {a,b,c,d,e }}$, Johanne Seguin ${ }^{\text {a,b,c,d }}$, Pierre-Louis Destruel ${ }^{\text {a,b,c,d,e }}$, Gilles Dumortier ${ }^{c}$, Marc Maury ${ }^{\mathrm{f}}$, Hélène Dhotel $^{\text {a,b,c,d }}$, Michel Bessodes ${ }^{\text {a,b,c,d }}$, Daniel Scherman ${ }^{\text {a,b,c,d, }}$, Nathalie Mignet ${ }^{\text {a,b,c,d }}$, Vincent Boudy $\mathrm{a}, \mathrm{b}, \mathrm{c}, \mathrm{d}, \mathrm{g}$ *

a- Chimie ParisTech, PSL Research University, Unité de Technologies Chimiques et Biologiques pour la Santé (UTCBS), F-75005 Paris, France

b- CNRS, UTCBS UMR 8258, F-75006 Paris, France

c- Université Paris Descartes, Sorbonne-Paris-Cité, F-75006 Paris, France

d- INSERM, UTCBS U 1022, F-75006 Paris, France

e- Unither Pharmaceuticals, 41, rue de la chaussée d'Antin, F-75009, Paris, France

f- Unither Développement Bordeaux, ZA Tech Espace, av Toussaint Catros, Le Haillan F-33185, France

g- Mise au point galénique, Agence Générale des Equipements et des Produits de Santé (AGEPS), AP-HP, 7, rue du Fer à moulin, F-75005, Paris, France

\begin{abstract}
Buccal administration route is a promising way for a large number of drugs exhibiting a low oral bioavailability. The present work describes the formulation and evaluation of a mucoadhesive and thermosensitive in situ gelling delivery system based on poloxamer 407, poloxamer 188 and xanthan gum for buccal drug delivery. First, the mucoadhesion properties were evaluated using a tensile test. The effect of xanthan gum on the mucoadhesion force was demonstrated. Then, the validation of a fluorescence probe for in vivo residence time experiment was conducted. Methyl-Cyanine 5 derivative (Me-Cy5) was used to label the hydrogels, dissolution tests and permeation studies through buccal epithelium cells showed that Me-Cy5 release from hydrogels was mainly due to an erosion mechanism and presented a limited penetration across epithelium cells. These results suggest that, Me-Cy5 is a suitable marker for thermosensitive in situ gelling delivery systems as the probe mostly stays entrapped in the hydrogel and do not cross the epithelial barrier. Buccal residence performance of the hydrogel was evaluated for the first time by non-invasive optical imaging after administration to mice. This technique is an interesting alternative compared to visual observations and sacrifice involved experiments, which could also be exploited to various administration routes. The intensity profiles indicated an extended residence time in the
\end{abstract}


buccal cavity for the formulations containing xanthan gum, suggesting a correlation between the mucoadhesion properties and the in vivo residence time.

Keywords: Buccal drug delivery, hydrogel, mucoadhesion, cyanine dye, optical imaging, fluorescence.

\section{Introduction}

For a large number of drugs, from small chemical compounds to large and complex structured proteins, the relatively low oral bioavailability has conducted researchers to find new administration routes [1]. Instinctively, buccal administration of drugs appeared as an alternative in terms of patient compliance and ease of administration. Furthermore, buccal drug delivery is considered as an interesting route of administration for the populations with swallowing disorders, such as pediatric patients and elderly people [2]. Buccal mucosa provides many advantages for local or systemic therapy [3]. Indeed, buccal administration of drugs allows avoiding the first pass hepatic metabolism as well as the proteolytic activity of the gastrointestinal tract [4] increasing drastically the bioavailability [5,6]. Therefore, buccal administration route has raised a large interest during the last two decades. One of the major issues in buccal drug delivery is to obtain an optimal localized concentration of the active pharmaceutical ingredient in the buccal cavity over a sufficiently long period of time. Unfortunately, this is difficult because of the salivation and tongue movements resulting in a rapid evacuation [7] and therefore, in the absorption of a small fraction of drugs by the buccal mucosa $[8,9]$. Actually, buccal administration of drugs by conventional forms, often leads to low bioavailability.

To overcome the drawbacks of existing buccal forms, a wide variety of solid and semi-solid delivery systems that adhere to the buccal mucosa and remain in place for a considerable time, such as bioadhesive patches and films [10-13], adhesive tablets [14-16], bioadhesive wafers and matrices [17-20], or hydrogels [21] have been developed. These pharmaceutical forms enable the sustained release of the drug and improve its bioavailability.

As another promising way to achieve efficient buccal drug delivery, a few investigators have considered the use of in situ gelling delivery systems as potential buccal dosage forms $[22,23]$. As a result of their physicochemical properties, in situ gelling systems allow a liquid administration into the buccal cavity and exhibit a sol to gel transition once in the buccal environment. Most of the time, this phase transition is observed for stimuli responsive polymeric formulations under variations of $\mathrm{pH}$ or temperature. On the one hand, the liquid phase allows the formulation spreading over a larger area than solid forms, resulting 
in a larger surface of absorption. On the other hand, the gel phase allows prolonging the time residence of the formulation in the buccal cavity. Thus, in situ gelling systems exhibit the main requirements of a buccal dosage form. The developed hydrogels should exhibit suitable mechanical and mucoadhesive properties including appropriate viscosity, ease of dispersion at the mucosa surface, and extended residence time in the buccal cavity.

In the literature, several studies show the impact of adding mucoadhesive polymers into a buccal form to enhance its time residence in the buccal cavity [24-26]. The adhesive polymers can be classified as synthetic and natural molecules, charged and uncharged types. The natural bioadhesive polymers, like chitosan [27], hyaluronic acid [28] and various gums (guar, alginate, xanthan, carrageenan) [29,30], are considerably developed because of their biocompatibility, biodegradability and low toxicity. Xanthan gum, obtained by the fermentation of the bacterium Xanthomonas campestris, is an anionic polysaccharide. It represents an attractive biopolymer for a variety of biomedical and pharmaceutical applications [31]. It has also been demonstrated to possess mucoadhesive properties in the development of ophthalmic devices [32,33].

The first part of this work focuses on the measurement of the mucoadhesive properties of a previously described thermosensitive in situ gelling system for buccal administration [34]. A series of hydrogels based on the mixture of poloxamer analogs and xanthan gum have been studied for buccal delivery of Salbutamol. Their thermal, mechanical, rheological and drug release properties had been investigated. The combination of P407, P188 and Satiaxane ${ }^{\circledR}$ (xanthan gum) provided not only an optimal sol-gel transition temperature (28$34^{\circ} \mathrm{C}$ ), but also an enhanced gel strength, which sustained the drug release especially in the presence of Satiaxane®.

The determination of the adhesive strength between the formulation and the biological substrate is typically used to assess mucoadhesion capacity. Different apparatus have been described to determine forces of detachment using shearing, tensile or peeling methods [35]. Many works reported the use of animal mucosa tissue [36-38]. However, using animal mucosa tissue raises conservation problems and requires an intimate fixation of the tissue on the dynamometer plate which is very difficult to achieve in a reproducible way. In this context, a mucin film technique was used in this study to avoid the concerns of tissue conservation and proved effective to demonstrate Satiaxane ${ }^{\circledR}$ mucoadhesive properties [34].

The second part of this work focuses on the validation of a Cyanine derivative as a suitable marker for the in vivo visualization of the previously developed hydrogel [34]. In order to visualize and track the hydrogel in vivo, a derivative of Cyanine 5 was synthesized in 
order to interact with the hydrophobic part of the pluronic triblock copolymers and incorporated into the hydrogel to label the form. To validate the methyl cyanine 5 derivative (Me-Cy5) as a suitable marker of our hydrogels, and detect the hydrogels in vivo, dissolution test and epithelium permeation test on $\operatorname{Transwell}^{\circledR}$ device were carried out. The human buccal epithelium was formed by culturing TR146 cells, which originate from a neck node metastasis of a human buccal epithelium carcinoma [39]. Finally, in vivo study in mice was performed by optical imaging, the time-response profile of fluorescence intensity in the buccal zone reflects the duration of the formulation residence.

\section{Materials and methods}

\subsection{Materials}

All the hydrogels were prepared using sterile water Versylene ${ }^{\circledR}$ purchased from Fresenius Kabi France (Sèvres, France). Salbutamol sulfate (SS) of European Pharmacopoeia grade (molecular weight $576.7 \mathrm{~g} / \mathrm{mol}$ ) was purchased from Farmalabor srl (Canosa di Puglia, Italy). Kolliphor ${ }^{\circledR}$ P407 and Kolliphor ${ }^{\circledR}$ P188 of pharmaceutical use grade were a kind gift from BASF (Ludwigshafen, Germany). Satiaxane ${ }^{\circledR}$ UCX930 (xanthan gum) was generously provided by Cargill France (Saint-Germain-en-Laye, France). The porcine gastric mucin type II was purchased from Sigma-Aldrich (St. Louis, MO). The fluorescence probe Me-Cy5 was synthetized in our laboratory.

\subsection{Synthesis of 1,1',3,3,3',3'-hexamethylindodicarbocyanine (Methyl-Cy5)}

Compound 1 (Fig. 1) was adapted from the protocol described by Jung and Kim [40]. The reaction scheme appears on Figure 1.

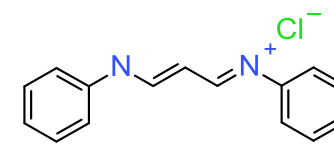

1<smiles>C=C1N(C)c2ccccc2C1(C)C</smiles>

2

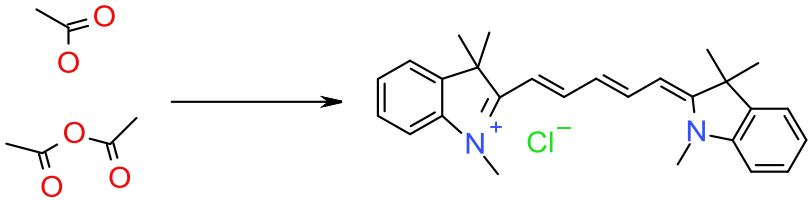

3

Fig. 1. Schematic synthesis of the methyl cyanine-5 derivative used in this study

Compounds $1(1 \mathrm{~g}, 3.88 \mathrm{mmol})$ and $2(2.8 \mathrm{~mL}, 2.1 \mathrm{eq})$ were dissolved in acetic acid (5 $\mathrm{mL})$, acetic anhydride $(5 \mathrm{~mL})$ was added and the mixture was heated 1 hour at $110{ }^{\circ} \mathrm{C}$. The solution turns intense blue rapidly. It was then evaporated under reduced pressure and the residue was chromatographed on silica gel, first eluted with $\mathrm{CH}_{2} \mathrm{Cl}_{2}$ where a yellow 
compound was discarded and then with a $\mathrm{CH} 2 \mathrm{Cl} 2 / \mathrm{MeOH}$ mixture (95:5) to elute the expected blue product. TLC (DCM/MeOH 8:2) $\mathrm{RF}=0.5$. The fluorescent marker was found to have an excitation wavelength of $650 \mathrm{~nm}$ and an emission wavelength of $670 \mathrm{~nm}$ as expected.

NMR characterizations were as follows:

${ }^{1} \mathrm{H} \quad \mathrm{NMR}(400 \mathrm{MHz}, \mathrm{DMSO}-\mathrm{d} 6): \delta 8.34 \mathrm{ppm}(2 \mathrm{H}, \mathrm{t}) ; 7.62 \mathrm{ppm}(2 \mathrm{H}, \mathrm{d}) ; 7.41 \mathrm{ppm}(4 \mathrm{H}, \mathrm{m})$; $7.25 \mathrm{ppm}(1 \mathrm{H}, \mathrm{m}) ; 6.55 \mathrm{ppm}(2 \mathrm{H}, \mathrm{t}) ; 6.30 \mathrm{ppm}(2 \mathrm{H}, \mathrm{dd}) ; 3.6 \mathrm{ppm}(6 \mathrm{H}, \mathrm{s}) ; 1.70 \mathrm{ppm}(12 \mathrm{H}, \mathrm{s})$

${ }^{13} \mathrm{C}$ NMR (400 MHz, DMSO-d6): $\delta$ 173.27, 153.88, 153.90, 142.70, 142.50, 140.90, 140.88, 128.32 , 124.24, 124.18, 124.20, 122.42, 122.46, 118.94, 118.79, 118.64, 110.92, 103.81, $103.20,48.87,31.02,27.53,26.78,26.32$.

\subsection{Hydrogel preparation}

The hydrogel was prepared according to Zeng's protocol [34]. Concentrations of all the components reported here are expressed as weight/volume percentage (\% w/v). P407 (17$19 \%)$ or P407 combined with P188 (1\%) were slowly added to a certain volume of sterile water, and then the preparations were left at $4{ }^{\circ} \mathrm{C}$ until clear solutions were obtained. The preparations were then gently homogenized with magnetic stirrers. Sterile water was then added to adjust the volume to the total amount.

For preparations containing Satiaxane ${ }^{\circledR}$, the Satiaxane ${ }^{\circledR}(0.05-0.1 \%)$ solutions were first prepared by dispersing the required amount in a certain volume of sterile water, stirring continuously until complete dissolution. Then the required amount of P407 and P188 were added to the already swollen Satiaxane ${ }^{\circledR}$ solution. The following procedures were the same as described above. When needed, SS of $0.2 \%$ was added and dissolved last, then the clear and homogeneous solutions were adjusted to a $\mathrm{pH}$ value between 3.0 and 3.5 by $0.4 \mathrm{M}$ sulfate acid to get molecule chemical stability [41]. It has to be noted that the final concentrations of other excipients (Poloxamers, Satiaxane ${ }^{\circledR}$ ) have to remain the same. The sample was shaken to have a homogeneous stained preparation, and then stored in refrigerator at $4^{\circ} \mathrm{C}$ for further study. The compositions of prepared formulations are shown in Table 1, and the applied codes are the same as in our first publication [34].

\section{Table 1}

Prepared and tested formulations

\begin{tabular}{llll}
\hline Formulation Code & P407 & P188 & Satiaxane $^{\circledR}$
\end{tabular}




\begin{tabular}{llll}
\hline & $(\%)$ & $(\%)$ & $(\%)$ \\
\hline F7 & 18 & 1 & - \\
F8 & 18 & 1 & 0.05 \\
F9 & 18 & 1 & 0.1 \\
F14 & 19 & 1 & - \\
F15 & 19 & 1 & 0.05 \\
F16 & 19 & 1 & 0.1 \\
\hline
\end{tabular}

P407: Kolliphor ${ }^{(}$P407; P188: Kolliphor ${ }^{\circledR}$ P188; Satiaxane ${ }^{\circledR}$ : Xanthan gum

\subsection{In vitro mucoadhesion evaluation using tensile test}

The mucoadhesive capacity of the various formulations was evaluated by measuring the force required to detach the formulations from a mucin film in a tensile test. It involved a software-controlled dynamometer MTS Synergie 1000 (Creteil, France) equipped with two stainless steel plates with a $50 \mathrm{~mm}$ diameter and a detector with a capacity of $100 \mathrm{~N}$. Porcine gastric mucin was used as biological substrate. A 5\% (weight/volume) mucin dispersion was previously prepared in sterile water. Mucin film was prepared directly on the lower plate: 100 $\mu \mathrm{L}$ of mucin dispersion were placed and spread on the plate in a homogeneous way. Then the surface was dried for 1 min with a dryer. $300 \mu \mathrm{L}$ of hydrogel were then put carefully on the lower plate covered by the mucin film. After a contact of 1 min with the hydrogel, the upper plate linked with the detector was moved upward at a constant speed of $10 \mathrm{~mm} / \mathrm{min}$ until the complete break of the hydrogel. At least five replicate analyses were performed for each formulation at $20^{\circ} \mathrm{C}$, using a fresh sample and a fresh mucin film in each case. The force of detachment $(\mathrm{N})$ as a function of displacement was recorded by the software. Then the maximum detachment force $\left(\mathrm{F}_{\max }\right)$ was analyzed and compared with the data obtained from the gel strength study without mucin film. The difference between the two forces, $\Delta \mathrm{F}_{\max }$, indicates the mucoadhesion capacity of the hydrogel.

\subsection{Evaluation of methyl-Cyanine 5 as a suitable fluorescence probe}

Me-Cy5 was then loaded in the previously described hydrogels. Concerning the MeCy5 addition, it was first dissolved in water at a concentration of $1 \mathrm{mg} / \mathrm{mL}$. Then the required volume of the solution was added to pre-prepared hydrogels to obtain a final concentration of $0.1 \mathrm{mg} / \mathrm{mL}$.

\subsubsection{In vitro release evaluation using the USP 4 system}


For this investigation, USP 4 flow through apparatus [42] provided by the company SPS Pharma Services (Orléans, France) was used. Seven standard cells with a diameter of $22.6 \mathrm{~mm}$ were used in all experiments. Operated in the closed configuration, the automated system CE7 smart Sotax (Basel, Switzerland) was linked to a piston pump Sotax CP7-50 (Basel, Switzerland) and a UV-VIS spectrophotometer Lambda 20 Elmer Perkin (Norwalk, USA) for a direct online analysis. In each cell, a ruby bead of $5 \mathrm{~mm}$ in diameter and glass beads of $1 \mathrm{~mm}$ in diameter were placed in the apex of flow-through cell. About $300 \mu \mathrm{L}$ hydrogel was placed into the glass beads bed. Before starting the test, the system was placed in a $37^{\circ} \mathrm{C}$ oven until the solution gelled and equilibrated. During the test, $50 \mathrm{~mL}$ PBS was pumped through each cell with a flow rate of $5 \mathrm{~mL} / \mathrm{min}$. Temperature of $37 \pm 0.5^{\circ} \mathrm{C}$ was maintained throughout the study. The concentration of Me-Cy5 was determined at regular intervals by spectrophotometer at $630 \mathrm{~nm}$. Samples were tested in triplicate. The release profiles obtained with the closed configuration, i.e., cumulative fraction of drug release $\left(\mathrm{M}_{\mathrm{t}} / \mathrm{M}_{\infty}, \%\right)$ versus time ( $\left.\mathrm{t}, \mathrm{min}\right)$, were plotted.

After obtaining release profiles, mathematical models such as Higuchi, zero-order, Korsmeyer-Peppas and Peppas-Sahlin 2 were applied to point out the release mechanism. This has already been described in our previous work [34]. Release kinetics and the related mechanisms were determined by fitting the experimental data to the various models and are described in Table 2. All the calculations were performed using DDSolver [43].

The times for $50 \%$ and $80 \%$ release $\left(\mathrm{T}_{50}, \mathrm{~T}_{80}\right.$ respectively) were also calculated from the Korsmeyer-Peppas equation. Moreover, a comparison of release performances between Me-Cy5 and Salbutamol Sulfate was done.

\section{Table 2}

Applied mathematical models and their descriptions

\begin{tabular}{lll}
\hline $\begin{array}{l}\text { Mathematical } \\
\text { model }\end{array}$ & Equation & Description \\
\hline Higuchi & $\mathrm{M}_{\mathrm{t}} / \mathrm{M}_{\infty}=\mathrm{K}_{\mathrm{h}} \mathrm{t}^{1 / 2}$ & $\begin{array}{l}\text { Diffusion as release } \\
\text { mechanism }\end{array}$ \\
& & Dissolution (erosion) as \\
Zero order & $\mathrm{M}_{\mathrm{t}} / \mathrm{M}_{\infty}=\mathrm{K}_{0} \mathrm{t}$ & release mechanism \\
& & $\mathrm{n}=0.5$, Fickian/diffusion- \\
\hline
\end{tabular}


controlled release;

$\mathrm{n}=1.0$, zero-order release;

$0.5<\mathrm{n}<1.0$, co-existence of

diffusion and erosion

Peppas-Sahlin $2 \quad \mathrm{M}_{\mathrm{t}} / \mathrm{M}_{\infty}=+\mathrm{K}_{1} \mathrm{t}^{1 / 2} \mathrm{~K}_{2} \mathrm{t}$

Separation of diffusion part

and dissolution part

Diffusion

proportion

$\mathrm{M}_{\mathrm{t} 1} / \mathrm{M}_{\mathrm{t}}=1 /\left(1+\left(\mathrm{K}_{2} / \mathrm{K}_{1}\right) \mathrm{t}^{1 / 2}\right) 100 \%$

Diffusion percentage to time

Dissolution proportion

$\mathrm{M}_{\mathrm{t} 2} / \mathrm{M}_{\mathrm{t}}=100 \%-1 /\left(1+\left(\mathrm{K}_{2} / \mathrm{K}_{1}\right) \mathrm{t}^{1 / 2}\right) 100 \%$

Dissolution percentage to time

$\mathrm{M}_{\mathrm{t}} / \mathrm{M}_{\infty}$ : fraction of drug release at each time point $\mathrm{t}$

$\mathrm{K}_{\mathrm{h}}$ : Higuchi release kinetic (diffusion) constant

$\mathrm{K}_{0}$ : zero-order kinetic constant

$\mathrm{K}_{\mathrm{kp}}$ : kinetic constant

$\mathrm{n}$ : release exponent which is indicative of release mechanism

$\mathrm{K}_{1}$ : diffusion constant, $\mathrm{K}_{2}$ : relaxation (erosion) constant

\subsubsection{Permeation evaluation using filter-grown TR146 cells}

It was important to know the Me-Cy5 probe's permeation performance on the buccal epithelium. As a formulation marker, it should be a marker of the formulation and therefore, not penetrate the organ nor the general circulation. To carry out this study, the TR146 cell line was cultivated, which was purchased from Cancer Research Technology (London, UK). For the cell permeability study, the Corning ${ }^{\circledR}$ Transwell@ polycarbonate membrane cell culture inserts (pore diameter $0.4 \mu \mathrm{m}$, growth area $1.12 \mathrm{~cm}^{2}$ ) which were purchased towards SigmaAldrich (St. Quentin Fallavier, France), were used to cultivate cells for 28 days [44]. The apical side and basolateral side were filled with 0.5 and $1.5 \mathrm{~mL}$ culture medium, which were changed twice a week. The cell culture medium Dulbecco's modified Eagle's medium (DMEM) with high glucose $4.5 \mathrm{~g} / \mathrm{L}$, GlutaMAXTM supplement and pyruvate, was provided by Life Technologies (Saint Aubin, France). Fetal bovine serum (FBS) and penicillin/streptomycin, were also obtained from Life Technologies (Saint Aubin, France). On the day of study, the culture medium of apical side was replaced by $200 \mu \mathrm{L}$ hydrogel supplemented with $200 \mu \mathrm{L}$ of fresh culture medium, which was considered as the donor 
compartment. The receptor compartment consisted of $1.5 \mathrm{~mL}$ PBS. Six samples of $100 \mu \mathrm{L}$ were collected from the receptor side at $0,0.5,1,2,3,4 \mathrm{~h}$. Before each sampling, the plate was shaken for about $1 \mathrm{~min}$. After the sampling, $100 \mu \mathrm{L}$ of fresh PBS were added in the receptor. Then the quantification of Me-Cy5 was carried out using a Wallac Victor2 1420 Multilabel Counter microplate reader provide by Perkin Elmer / Wallac (Massachusetts, US). The permeation fraction $(\%)$, flux $(\mathrm{F})\left(\mu \mathrm{g} /\left(\mathrm{cm}^{2} \times \mathrm{h}\right)\right)$ and apparent permeability coefficient $\left(\mathrm{P}_{\text {app }}\right)$ $(\mathrm{cm} / \mathrm{h})$ were calculated.

\subsection{In vivo fluorescence imaging in mice using the portable system Fluobeam ${ }^{\circledR}$}

This animal research project, in conformity with the regulations of Committee on Ethics in the care and use of laboratory animals, was authorized by Ministry of higher education and research with the reference 00733.01. Male inbred mice BALB/C were purchased from Janvier Labs (Le Genest Saint Isle, France). The in vivo experiments were performed in non-anesthetized mice, which were only razed at the zones of interest. $10 \mu \mathrm{L}$ of preparation was carefully administered to animal's buccal cavity with a micro syringe equipped with round-tip needle. Fluobeam ${ }^{\circledR}$, provided by Fluoptics (Grenoble, France), is a portable imager providing a zoom and an autofocus enabling to image with a very high sensitivity the complete surgical field and then to focus on regions of interest. In our study, the camera was fixed towards paillasse at a constant distance to obtain optimal images. Laser and LED lights were used to visualize the fluorescence signal. The software allowed acquiring images. The acquisition was performed immediately after the formulation administration, and the fluorescence intensity of the initial moment was considered as control (100\%). The selected formulation F16 with P407 19\%, P188 1\% and Satiaxane ${ }^{\circledR} 0.1 \%$ containing Me-Cy5 was compared to the Me-Cy5 solution at $0.1 \mathrm{mg} / \mathrm{mL}$. The kinetic data was finally obtained by analyzing the images by open source processing program Image $\mathrm{J}$.

\subsection{Statistical analysis}

The statistical significance of the obtained values was analyzed using one-way ANOVA and repeated two-way ANOVA $(p<0.05)$ (Statview 5, SAS Institute, Cary, NC, USA).

\section{Results and Discussion}

\subsection{In vitro mucoadhesion measurement using tensile test}


The assessment was carried out only at $20^{\circ} \mathrm{C}$, because at $37^{\circ} \mathrm{C}$, the sample being at the gel state, its strong intrinsic strength renders the determination of adhesive interactions less sensible and discriminant.

In tensile test, the maximum detachment forces of hydrogels from the mucin film $\mathrm{F}_{\max }$ were measured and compared to the values obtained in the tests without mucin. The results are presented in Fig. 2. When comparing $F_{\max }$ values with mucin to those without mucin, here expressed as $\Delta \mathrm{F}_{\max }$, a significant increase was observed for all the formulations $(p<0.0001)$. This indicates the force of the interaction between hydrogel and the mucin. $\Delta \mathrm{F}_{\max }$ values of formulations containing Satiaxane ${ }^{\circledR}$, F8, F9, F15 and F16, were higher than those without Satiaxane ${ }^{\circledR}$ F7 and F14, independently of the amount of P407. The highest value of $F_{\max }$ with mucin was obtained at $33.94 \pm 2.66 \mathrm{~N}$ for $\mathrm{F} 16$, which corresponds to a $\Delta \mathrm{F}_{\max }$ of $11.48 \mathrm{~N}$. Concerning the formulations without Satiaxane ${ }^{\circledR} \mathrm{F} 7$ and $\mathrm{F} 14, \Delta \mathrm{F}_{\max }$ were $4.35 \mathrm{~N}$ and $6.67 \mathrm{~N}$.

Several studies have demonstrated the advantages of xanthan gum as bio/mucoadhesive material: in buccal patch [45], ophthalmic hydrogel [46] or vaginal hydrogel [47]. As a natural biocompatible polymer, xanthan gum has a $\beta$-(1 $\rightarrow 4)$-D-glucose backbone where every second glucose unit is attached to a trisaccharide consisting of mannose, glucuronic acid, and mannose. The anionic character of this polymer is related to the presence of both glucuronic acid and pyruvic acid groups in the side chain [29]. Generally, ionic polymers exhibit stronger mucoadhesive strength than non-ionic polymers [48]. It was reported that the mucoadhesiveness of weakly anionic carboxyl-containing polymers is often related to the ability of carboxylic groups to form hydrogen-bonds with oligosaccharide chains of mucins [48]. The addition of xanthan gum into non-ionic poloxamer based gels could be expected to give an enhanced resistance of the formulation in vivo. Consequently, formulations containing Satiaxane ${ }^{\circledR}$ F8, F9, F15 and F16 were chosen to incorporate Me-Cy5. 


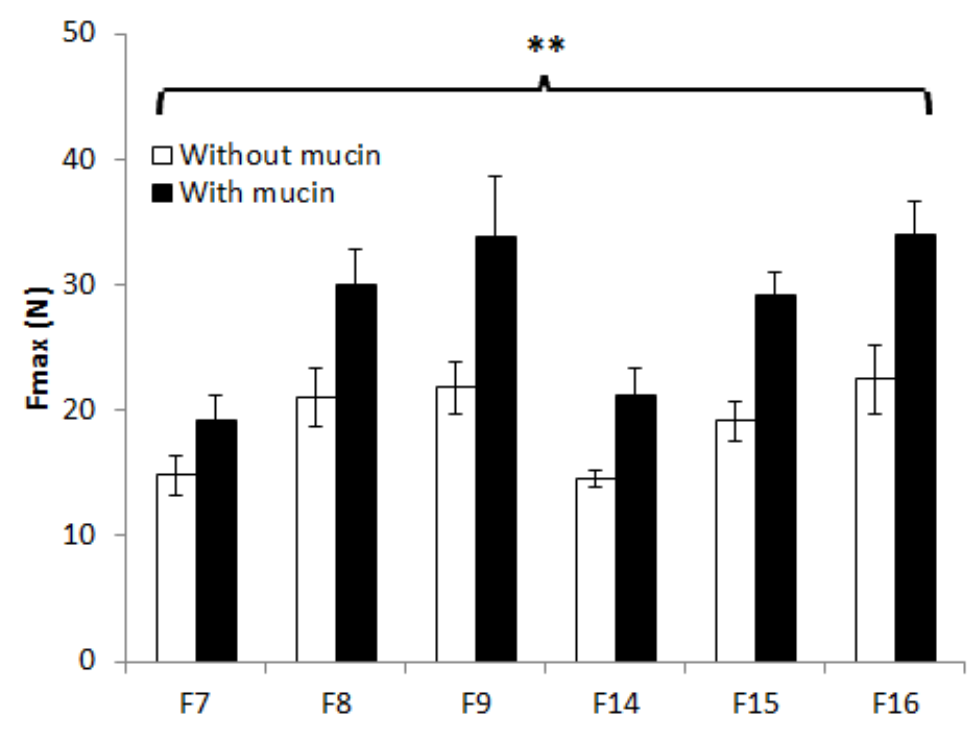

Fig. 2. Mucoadhesive strength measurements of the various formulations ( $n=5)$. F7: P407 18\%/P188 1\%; F8: P407 18\%/P188 1\%/Satiaxane 0.05\%; F9: P407 18\%/P188 1\%/Satiaxane 0.1\%; F14: P407 19\%/P188 1\%; F15: P407 19\%/P188 1\%/Satiaxane 0.05\%; F16: P407 19\%/P188 1\%/Satiaxane 0.1\%. **Difference between values with and without mucin, $p<0.0001$.

\subsection{Validation of Me-Cy5 as a suitable hydrogel marker}

\subsubsection{Me-Cy5 release behaviors and mechanisms}

When the hydrogel is administered to buccal mucosa, it can be dissolved by the saliva or eroded by the tongue. Generally, drugs, especially hydrophilic molecules, can easily be released from the hydrogel and are expected to diffuse freely outside of the gel. On the contrary, a hydrogel marker should be able to remain "trapped" in the hydrogel. In terms of dissolution behaviors, its release should be conducted by dissolution/erosion phenomenon, whereas the diffusion should be minimized. To study these properties, release tests based on the USP4 apparatus and mathematical modelling were applied.

Me-Cy5 release profiles of the various formulations containing Satiaxane ${ }^{\circledR}$ are shown in Fig. 3. Similarly to our previous observations in the case of the salbutamol drug [34], F16 containing the highest content of P407 and Satiaxane ${ }^{\circledR}$ showed the slowest release. 


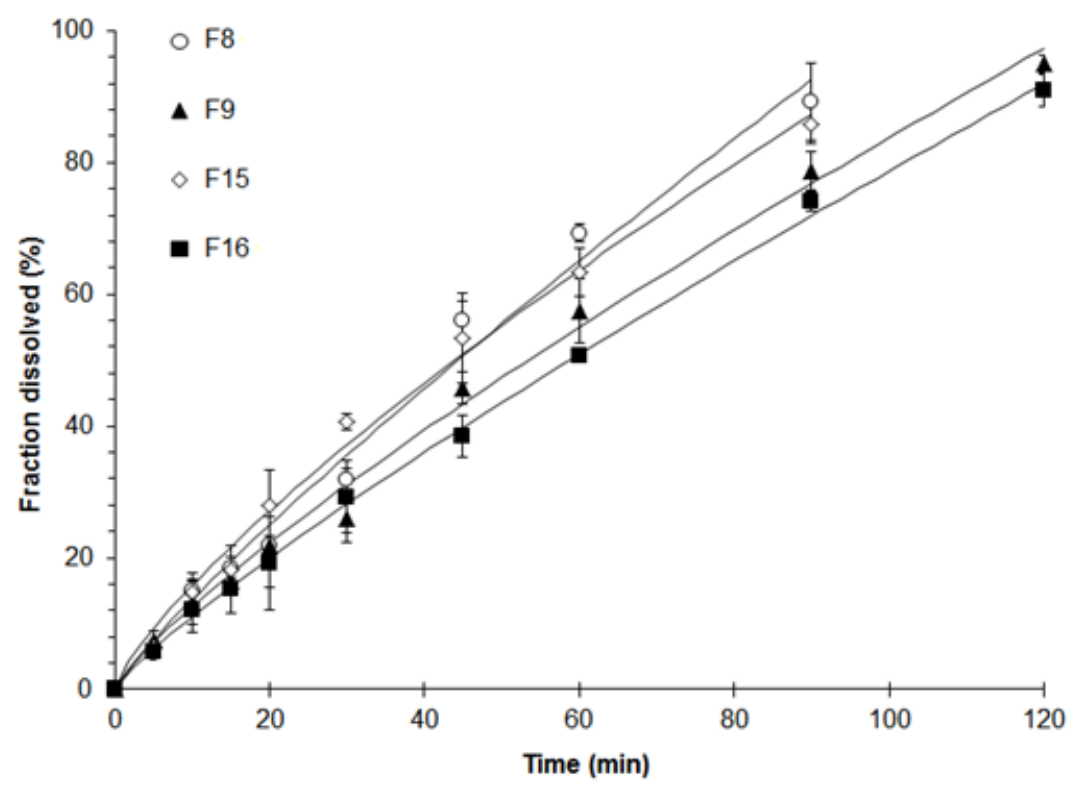

Fig. 3. Me-Cy5 release behaviors from the tested hydrogels, obtained by USP 4 Flow through standard cell. Values are expressed as means \pm SD (n=3). F8: P407 18\%/P188 1\%/Satiaxane 0.05\%; F9: P407 18\%/P188 1\%/Satiaxane 0.1\%; F15: P407 19\%/P188 1\%/Satiaxane 0.05\%; F16: P407 19\%/P188 1\%/Satiaxane 0.1\%.

When release behaviors were further analyzed by mathematical models, the Peppas equations and zero-order kinetics were shown more suitable regarding the values of $\mathrm{R}_{\text {ajusted }}$ (Table S1). The zero-order equation provided higher $\mathrm{R}_{\text {ajusted }}$ than Higuchi model which reflected diffusion phenomenon. Furthermore, in Korsmeyer-Peppas model, the values of $n$ were found between 0.5 and 1 , which indicated the superposition of diffusion and erosion mechanisms.

The values of $\mathrm{T}_{50}$ and $\mathrm{T}_{80}$ confirmed the fact that increasing Satiaxane ${ }^{\circledR}$ concentration extended the release of Me-Cy5 (Table 3). In addition, when comparing the profiles of MeCy5 and Salbutamol (SS), Me-Cy5 release was slower than SS, with longer $\mathrm{T}_{50}$ and $\mathrm{T}_{80}$. Moreover, when comparing $\mathrm{n}$ values of Me-Cy5 and SS, the higher values of Me-Cy5 suggested that erosion part became more important. Based on Peppas-Sahlin 2 model, the repartition of diffusion and erosion mechanisms is illustrated in Fig. 4. We found that the release mechanism of Me-Cy5 was totally different from that of SS, and that erosion remained the predominant mechanism over the period tested.

\section{Table 3}

Values of $\mathrm{n}$, times for $50 \%$ and $80 \%$ of release obtained from Korsmeyer-Peppas model: Comparison between Me-Cy5 and Salbutamol 


\begin{tabular}{ccccccc}
\hline & & Me-Cy5 & & \multicolumn{3}{c}{ Salbutamol Sulfate } \\
& & $\mathrm{T}_{50}$ & $\mathrm{~T}_{80}$ & & $\mathrm{~T}_{50}$ & $\mathrm{~T}_{80}$ \\
& $\mathrm{n}$ & $(\mathrm{min})$ & $(\mathrm{min})$ & $\mathrm{n}$ & $(\mathrm{min})$ & $(\mathrm{min})$ \\
\hline $\mathrm{F} 8$ & 0.87 & 44.3 & 76.0 & 0.62 & 25.8 & 55.4 \\
F9 & 0.82 & 53.4 & 94.6 & 0.70 & 34.2 & 67.3 \\
F15 & 0.78 & 44.0 & 80.4 & 0.53 & 21.0 & 50.7 \\
F16 & 0.85 & 58.8 & 102.0 & 0.64 & 35.4 & 73.5 \\
\hline
\end{tabular}

A

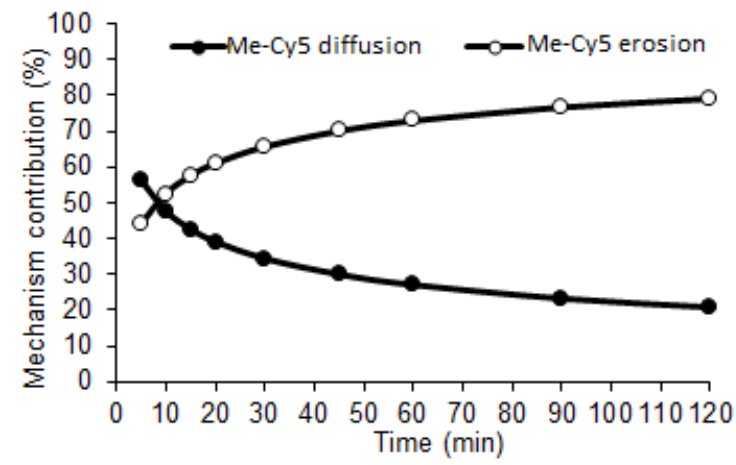

B

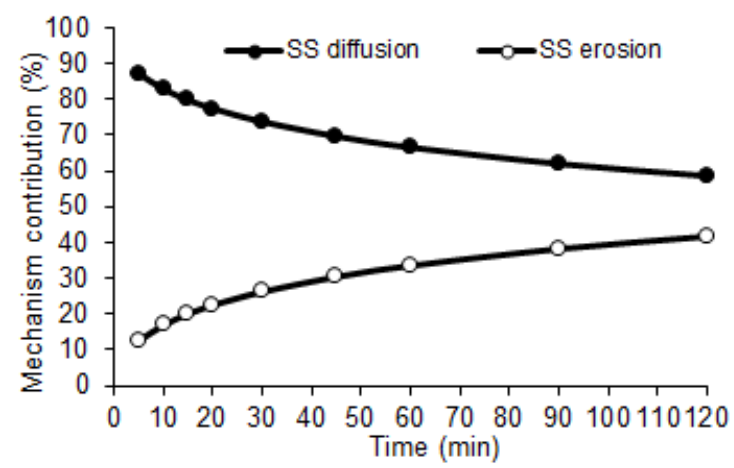

Fig. 4. Percentage of diffusion and erosion contributions as a function of time, in the case of F16. A) Me-Cy5 profiles; B) SS profiles

The different release profiles between Me-Cy5 and SS might be explained by their physicochemical properties. SS has a molecular weight of $576.7 \mathrm{~g} / \mathrm{mol}$ while the molecular weight of Me-Cy5 is $418.2 \mathrm{~g} / \mathrm{mol}$. SS solubility values at pH 3 and $\mathrm{pH} 7.4$ are $263.5 \mathrm{mg} / \mathrm{mL}$ 
and $261.6 \mathrm{mg} / \mathrm{mL}$, respectively [49]. On the contrary, Me-Cy5 is a weakly hydrosoluble agent $(\sim 0.1 \mathrm{mg} /$ at $\mathrm{pH}<7)$. Besides, SS shows a lower lipophilicity $(\log \mathrm{P}=-1.664)$ compared to MeCy5 $(\log \mathrm{P}=3.291)$ [50]. We can hypothesize that Me-Cy5 is probably dissolved thanks to the poloxamer micelles. Unlike SS, Me-Cy5 low solubility and lipophilic properties dramatically slow down its diffusion and release from the hydrogel, this makes it a valuable marker of hydrogels.

\subsubsection{Me-Cy5 permeation behaviors}

Permeation study was performed on stratified TR146 cells. As shown in Fig. 5A, all formulations exhibited similar behaviors, but F16 presented the slowest permeation, and a lag-time could be observed. This phenomenon was not observed in the permeation of Salbutamol. Fig. 5B and 5C allowed highlighting the difference between Me-Cy5 and SS. SS penetrated across epithelial cells more easily than Me-Cy5. Permeation flux was found more than 10 times lower than that of Salbutamol (Table S2) [51]. While 20\% of SS was found in the receptor compartment after 4 hours, less than 5\% of Me-Cy5 was found across the cells up to 4 hours.

These findings demonstrate the low diffusion capacity of Me-Cy5 across the gel and epithelium cell layers. Consequently, the Me-Cy5 met the main criteria to track the formulation in vivo: ability to remain in the gel (i) and probable negligible diffusion through the buccal mucosa (ii). 


\section{A)}

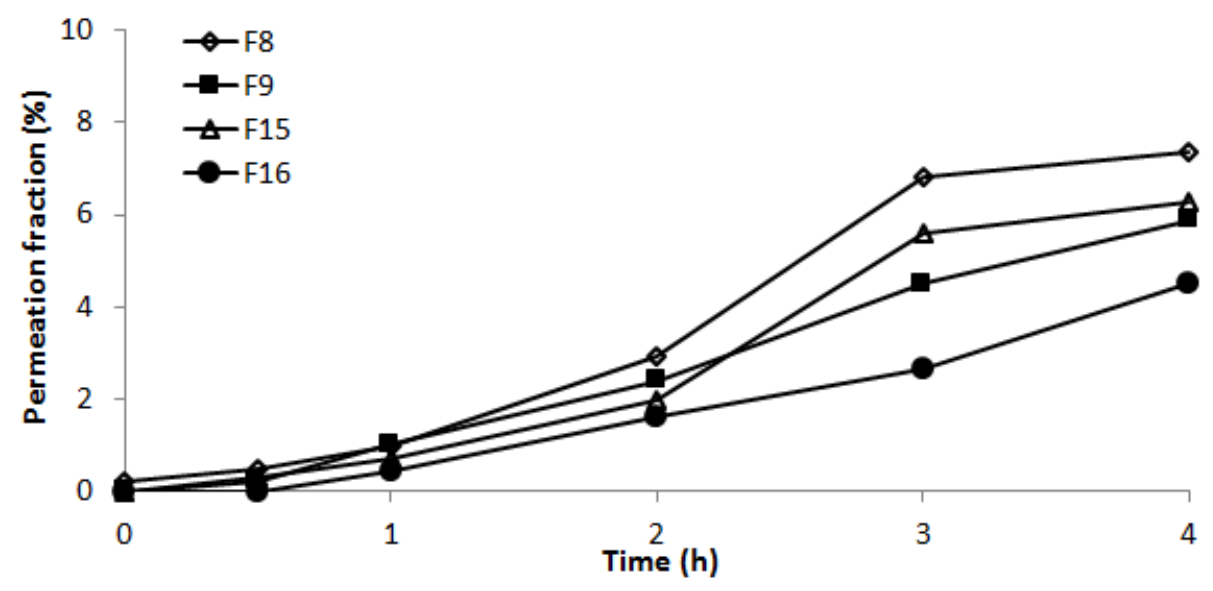

B)

C)
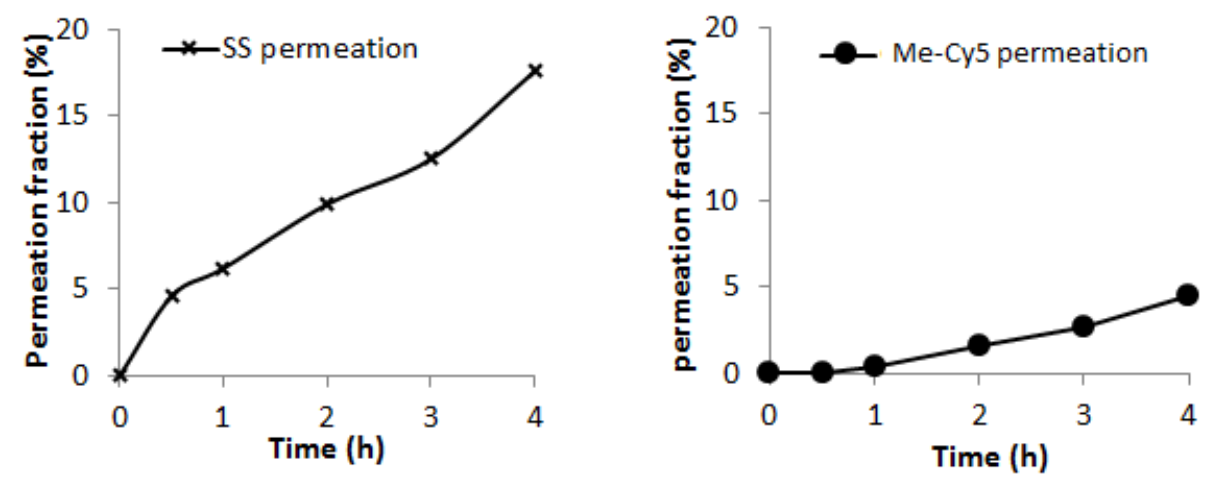

Fig. 5. A. Me-Cy5 permeation across stratified TR146 human epithelium cells. Values expressed as means of two or three experiments. F8: P407 18\%/P188 1\%/Satiaxane 0.05\%; F9: P407 18\%/P188 1\%/Satiaxane 0.1\%; F15: P407 19\%/P188 1\%/Satiaxane 0.05\%; F16: P407 19\%/P188 1\%/Satiaxane 0.1\%. B. SS permeation in the case of F16. C. Me-Cy5 permeation in the case of F16.

\subsection{In vivo evaluation by Fluobeam ${ }^{\circledR}$ imaging technique}

After having validated Me-Cy5 as a suitable hydrogel imaging probe, the selected formulation F16 incorporating Me-Cy5 was compared to the Me-Cy5 solution at the same concentration after administration at the buccal mucosa of non-anesthetized mice. Based on the above results, we considered that the evolution of the signal intensity in mice buccal cavity reflected the retention ability of hydrogels. Fig. 6 represents the experiment sites of administration and the images observed at different time points. The images were characterized by a satisfactory signal intensity and area change as a function of time. 

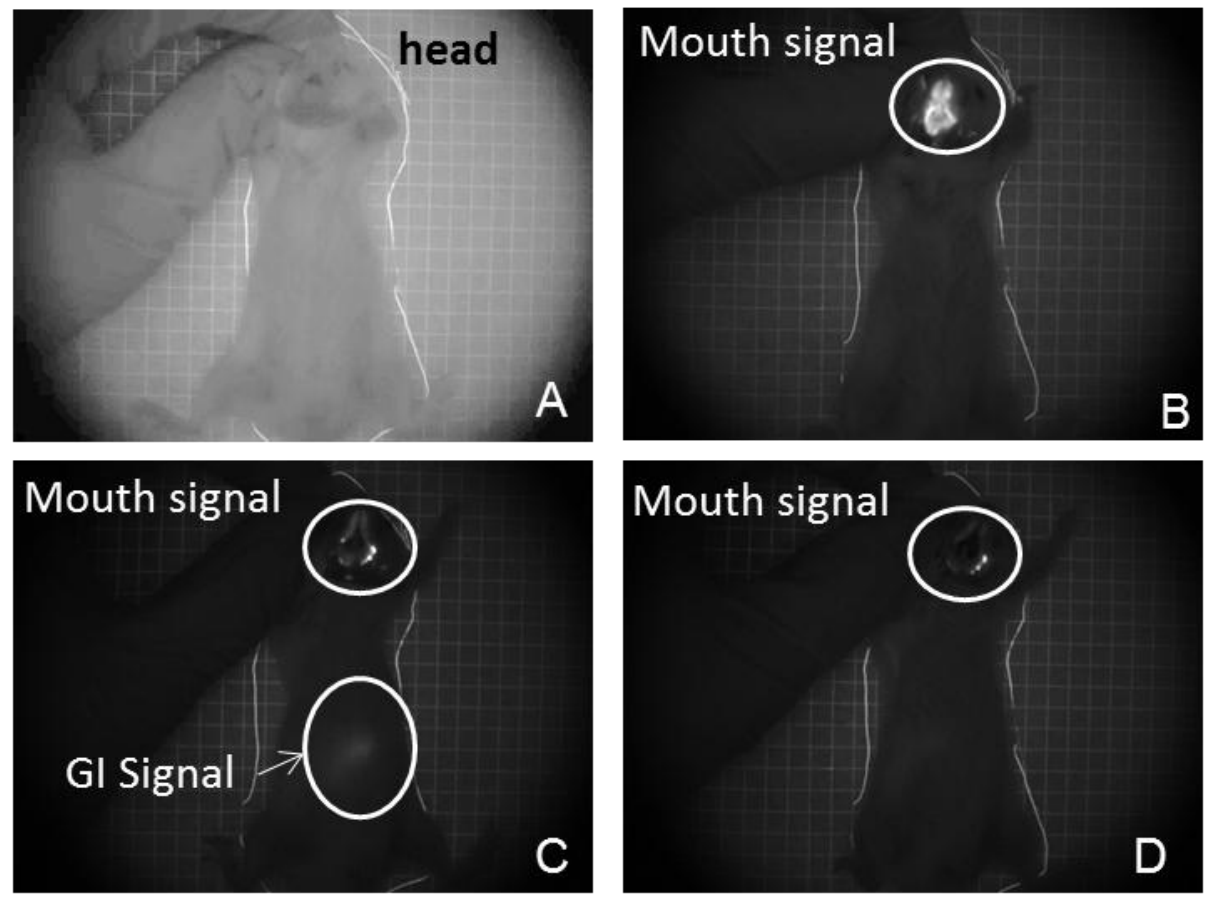

Fig. 6. Fluobeam ${ }^{\circledR}$ images: A) Before administration, optics image without LED and Laser; B) T0 of administration; C) T30 min; D) T3 hours.

The evolution of the fluorescence intensity normalized by the initial fluorescence signal is plotted in Fig. 6. As we can see, there is a significant difference between Me-Cy5 solution and the hydrogel formulation (Fig. 7). Table S3 shows the data at each time point. As expected, the Me-Cy5 solution was eliminated more rapidly than the Me-Cy5 entrapped within the gel. In F16, the signal intensity was about $80 \%$ at 5 minutes after administration, which suggests a good resistance of the hydrogel formulation. Furthermore, at the initial period, due to the stress, mice were not accustomed to the administration, and tended to eliminate the formulation by tongue movements and saliva secretion. After 3 hours, $30 \%$ still remained in the buccal area of mice. It has to be mentioned that the administered volume of formulations was only $10 \mu \mathrm{L}$ due to the limited buccal surface of mouse. A normal volume to human is expected to be about $200-300 \mu \mathrm{L}$, which could potentially increase the resistance time.

According to one phase decay, the area under curve AUC and half-time T 50\% were calculated and showed a significant difference between F16 and Me-Cy5 solution $(p<0.05)$ (Fig. 8). The median AUC value for encapsulated Me-Cy5 was increased by a factor 2 and Cy 5 half-time gained a factor 3 . This represents a highly interesting result when considering that the mice as vigile and that the hydrogel was submitted to tongue movements which promoted 
a fast elimination. These data provide interesting perspectives for analgesic delivery or delivery in areas less submitted to erosion.

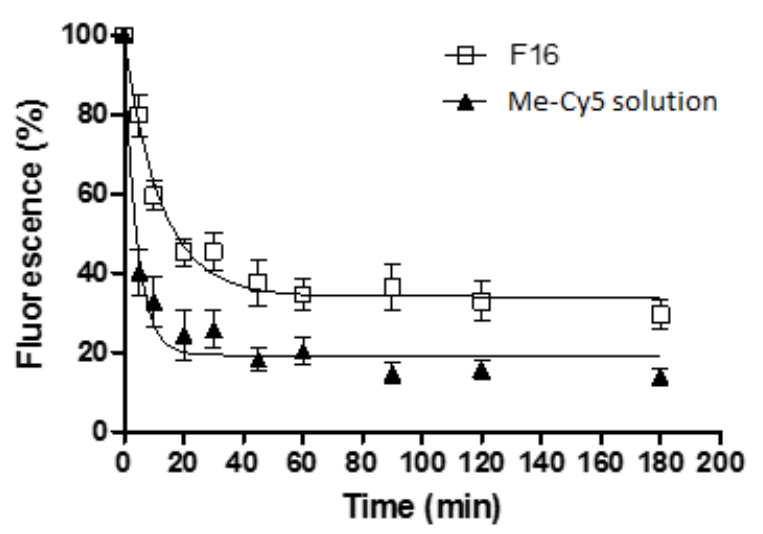

Fig. 7. Kinetic of signal reduction for Me-Cy5 within the gel as regard to Me-Cy5 solution administered in mice buccal cavity $(\mathrm{n}=6-7)$
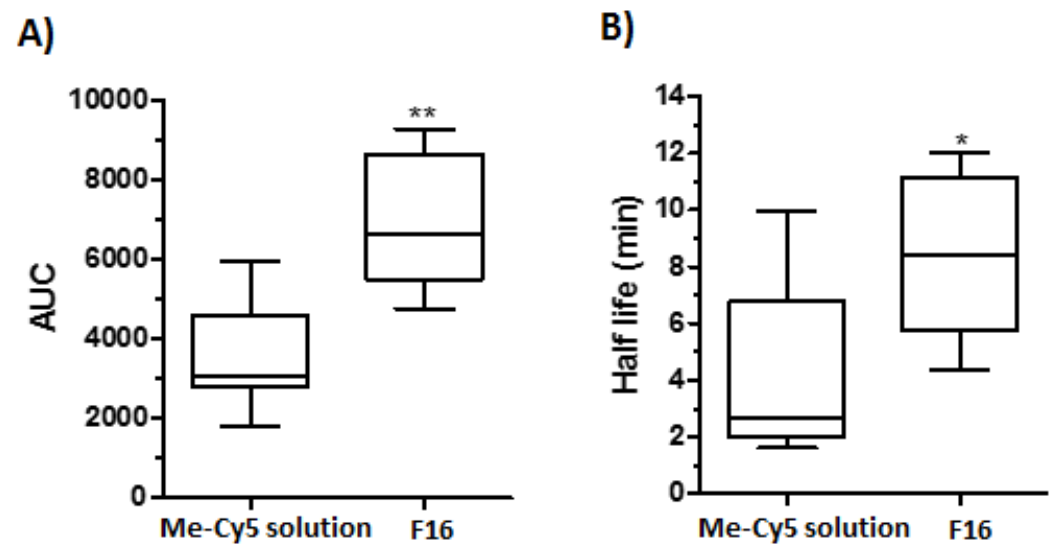

Fig. 8. A) AUC comparison of Me-Cy5 solution and hydrogel formulation F16; B) T50\% comparison of MeCy5 solution and hydrogel formulation F16. * $p<0.05$, ** $p<0.01$

There is very little in vivo works dedicated to preclinical studies on the residence performance of the formulations administered in the buccal cavity. Generally, the studies concern solid forms or patches by visual observation [52,53]. In the case of hydrogels, visual evaluation is very delicate to carry out. In this context, the incorporation of a fluorescent marker could provide accurate information about hydrogel's behavior in vivo. Another advantage is that the imaging technique use is non-invasive and provides kinetic data in a normal light environment. With a portable camera, the animals could be kept vigilant and no sacrifice was needed to analyze the fluorescence intensity. As compared to gamma scintigraphy technique, which is often used to study the performance of gastrointestinal 
form's [54], the physical incorporation of the marker used in our study is easier to realize and the technique is available in a larger number of laboratories. This technique could also be exploited in other drug administration routes, like ophthalmic, oral, rectal ways, etc, to evaluate the residence time of formulations at a specific site.

\section{Conclusion}

In this study, the in vitro mucoadhesion assessment demonstrated the interaction between our developed hydrogels and mucin. Satiaxane ${ }^{\circledR}$ (xanthan gum) showed effective in enhancing mucoadhesive properties of our formulations. The release methods confirmed the weak ability of the fluorescence probe Me-Cy5 to diffuse from the hydrogels. We showed that its release was mainly due to erosion. Additionally, the permeation behavior showed the limited permeation of Me-Cy5 molecules across buccal epithelial cells. These findings suggest that the Me-Cy5 dye that we have chosen, with its dimethyl groups, could be a suitable marker for tracking the poloxamer hydrogels in vivo. The in vivo assays in mice supported the interest of incorporating a fluorescent marker to visualizing and comparing the formulations. It also suggests that imaging technique is a relevant method to study the residence performance of mucoadhesive formulations.

\section{Acknowledgements}

The authors would like to thank Unither Pharmaceuticals for financial support to this project, and SPS Pharma Services for providing Sotax USP4 apparatus. 


\section{References}

[1] Y. Sudhakar, K. Kuotsu, A.K. Bandyopadhyay, Buccal bioadhesive drug delivery - A promising option for orally less efficient drugs, J. Controlled Release. 114 (2006) 15-40. doi:10.1016/j.jconrel.2006.04.012.

[2] J.K.W. Lam, Y. Xu, A. Worsley, I.C.K. Wong, Oral transmucosal drug delivery for pediatric use, Adv. Drug Deliv. Rev. 73 (2014) 50-62. doi:10.1016/j.addr.2013.08.011.

[3] V. Hearnden, V. Sankar, K. Hull, D.V. Juras, M. Greenberg, A.R. Kerr, P.B. Lockhart, L.L. Patton, S. Porter, M.H. Thornhill, New developments and opportunities in oral mucosal drug delivery for local and systemic disease, Adv. Drug Deliv. Rev. 64 (2012) 16-28. doi:10.1016/j.addr.2011.02.008.

[4] N. Bhattarai, J. Gunn, M. Zhang, Chitosan-based hydrogels for controlled, localized drug delivery, Adv. Drug Deliv. Rev. 62 (2010) 83-99. doi:10.1016/j.addr.2009.07.019.

[5] H.E. Junginger, J.A. Hoogstraate, J.C. Verhoef, Recent advances in buccal drug delivery and absorption - in vitro and in vivo studies, J. Controlled Release. 62 (1999) 149-159.

http://www.sciencedirect.com/science/article/pii/S0168365999000322 (accessed March 29, 2017).

[6] V.F. Patel, F. Liu, M.B. Brown, Advances in oral transmucosal drug delivery, J. Control. Release Off. J. Control. Release Soc. 153 (2011) 106-116. doi:10.1016/j.jconrel.2011.01.027.

[7] M.J. Rathbone, B.K. Drummond, I.G. Tucker, The oral cavity as a site for systemic drug delivery, Adv. Drug Deliv. Rev. 13 (1994) 1-22. http://www.sciencedirect.com/science/article/pii/0169409X94900248 (accessed March 29, 2017).

[8] N.V.S. Madhav, A.K. Shakya, P. Shakya, K. Singh, Orotransmucosal drug delivery systems: A review, J. Controlled Release. 140 (2009) 2-11. doi:10.1016/j.jconrel.2009.07.016.

[9] S. Rossi, G. Sandri, C.M. Caramella, Buccal drug delivery: A challenge already won?, Drug Discov. Today Technol. 2 (2005) 59-65. doi:10.1016/j.ddtec.2005.05.018.

[10] R.P. Dixit, S.P. Puthli, Oral strip technology: Overview and future potential, J. Controlled Release. 139 (2009) 94-107. doi:10.1016/j.jconrel.2009.06.014.

[11] I. Diaz del Consuelo, F. Falson, R.H. Guy, Y. Jacques, Ex vivo evaluation of bioadhesive films for buccal delivery of fentanyl, J. Controlled Release. 122 (2007) 135-140. doi:10.1016/j.jconrel.2007.05.017.

[12] J.O. Morales, J.T. McConville, Manufacture and characterization of mucoadhesive buccal films, Eur. J. Pharm. Biopharm. 77 (2011) 187-199. doi:10.1016/j.ejpb.2010.11.023.

[13] A.B. Nair, R. Kumria, S. Harsha, M. Attimarad, B.E. Al-Dhubiab, I.A. Alhaider, In vitro techniques to evaluate buccal films, J. Controlled Release. 166 (2013) 10-21. doi:10.1016/j.jconrel.2012.11.019.

[14] H.-G. Choi, J.-H. Jung, C.S. Yong, C.-D. Rhee, M.-K. Lee, J.-H. Han, K.-M. Park, C.-K. Kim, Formulation and in vivo evaluation of omeprazole buccal adhesive tablet, J. Controlled Release. 68 (2000) 405-412. http://www.sciencedirect.com/science/article/pii/S0168365900002753 (accessed March 29, 2017).

[15] H.-G. Choi, C.-K. Kim, Development of omeprazole buccal adhesive tablets with stability enhancement in human saliva, J. Controlled Release. 68 (2000) 397-404. http://www.sciencedirect.com/science/article/pii/S0168365900002765 (accessed March 29, 2017).

[16] G. İkinci, S. Şenel, C.. Wilson, M. Şumnu, Development of a buccal bioadhesive nicotine tablet formulation for smoking cessation, Int. J. Pharm. 277 (2004) 173-178.

doi:10.1016/j.ijpharm.2003.10.040. 
[17] I. Ayensu, J.C. Mitchell, J.S. Boateng, Development and physico-mechanical characterisation of lyophilised chitosan wafers as potential protein drug delivery systems via the buccal mucosa, Colloids Surf. B Biointerfaces. 91 (2012) 258-265. doi:10.1016/j.colsurfb.2011.11.004.

[18] S. Cafaggi, R. Leardi, B. Parodi, G. Caviglioli, E. Russo, G. Bignardi, Preparation and evaluation of a chitosan salt-poloxamer 407 based matrix for buccal drug delivery, J. Controlled Release. 102 (2005) 159-169. doi:10.1016/j.jconrel.2004.09.019.

[19] F. Kianfar, M. Antonijevic, B. Chowdhry, J.S. Boateng, Lyophilized wafers comprising carrageenan and pluronic acid for buccal drug delivery using model soluble and insoluble drugs, Colloids Surf. B Biointerfaces. 103 (2013) 99-106. doi:10.1016/j.colsurfb.2012.10.006.

[20] L.I. Giannola, V. De Caro, G. Giandalia, M.G. Siragusa, C. Tripodo, A.M. Florena, G. Campisi, Release of naltrexone on buccal mucosa: Permeation studies, histological aspects and matrix system design, Eur. J. Pharm. Biopharm. 67 (2007) 425-433. doi:10.1016/j.ejpb.2007.02.020.

[21] T. Nagai, Y. Machida, Buccal delivery systems using hydrogels, Adv. Drug Deliv. Rev. 11 (1993) 179-191. http://www.sciencedirect.com/science/article/pii/0169409X9390032Y (accessed March 29, 2017).

[22] N. Das, P. Madan, S. Lin, Development and in vitro evaluation of insulin-loaded buccal Pluronic F-127 gels, Pharm. Dev. Technol. 15 (2010) 192-208. doi:10.3109/10837450903085442.

[23] Ajazuddin, A. Alexander, J. Khan, T.K. Giri, D.K. Tripathi, S. Saraf, S. Saraf, Advancement in stimuli triggered in situ gelling delivery for local and systemic route, Expert Opin. Drug Deliv. 9 (2012) 1573-1592. doi:10.1517/17425247.2013.734806.

[24] N.A. Nafee, F.A. Ismail, N.A. Boraie, L.M. Mortada, Mucoadhesive Delivery Systems. I. Evaluation of Mucoadhesive Polymers for Buccal Tablet Formulation, Drug Dev. Ind. Pharm. 30 (2004) 985-993. doi:10.1081/DDC-200037245.

[25] N. Salamat-Miller, M. Chittchang, T.P. Johnston, The use of mucoadhesive polymers in buccal drug delivery, Adv. Drug Deliv. Rev. 57 (2005) 1666-1691. doi:10.1016/j.addr.2005.07.003.

[26] R.B. Gandhi, J.R. Robinson, Oral cavity as a site for bioadhesive drug delivery, Adv. Drug Deliv. Rev. 13 (1994) 43-74. doi:10.1016/0169-409X(94)90026-4.

[27] L. Ilium, Chitosan and Its Use as a Pharmaceutical Excipient, Pharm. Res. 15 (1998) 1326-1331. doi:10.1023/A:1011929016601.

[28] Y.-H. Liao, S.A. Jones, B. Forbes, G.P. Martin, M.B. Brown, Hyaluronan: Pharmaceutical Characterization and Drug Delivery, Drug Deliv. 12 (2005) 327-342. doi:10.1080/10717540590952555.

[29] T.R. Bhardwaj, M. Kanwar, R. Lal, A. Gupta, Natural gums and modified natural gums as sustained-release carriers, Drug Dev. Ind. Pharm. 26 (2000) 1025-1038. doi:10.1081/DDC100100266.

[30] M.A. Mughal, Z. Iqbal, S.H. Neau, Guar gum, xanthan gum, and HPMC can define release mechanisms and sustain release of propranolol hydrochloride, AAPS PharmSciTech. 12 (2011) 77-87. doi:10.1208/s12249-010-9570-1.

[31] R. Rowe, P. Sheskey, S. Owen, Handbook of Pharmaceutical Excipients, 5th ed., London UK and American Pharmaceutical Association, Washington, USA, 2005.

[32] M. Bhowmik, P. Kumari, G. Sarkar, M.K. Bain, B. Bhowmick, M.M.R. Mollick, D. Mondal, D. Maity, D. Rana, D. Bhattacharjee, D. Chattopadhyay, Effect of xanthan gum and guar gum on in situ gelling ophthalmic drug delivery system based on poloxamer-407, Int. J. Biol. Macromol. 62C (2013) 117-123. doi:10.1016/j.ijbiomac.2013.08.024.

[33] J. Ceulemans, I. Vinckier, A. Ludwig, The use of xanthan gum in an ophthalmic liquid dosage form: rheological characterization of the interaction with mucin, J. Pharm. Sci. 91 (2002) $1117-$ 1127. 
[34] N. Zeng, G. Dumortier, M. Maury, N. Mignet, V. Boudy, Influence of additives on a thermosensitive hydrogel for buccal delivery of salbutamol: relation between micellization, gelation, mechanic and release properties, Int. J. Pharm. 467 (2014) 70-83. doi:10.1016/j.ijpharm.2014.03.055.

[35] G.P. Andrews, T.P. Laverty, D.S. Jones, Mucoadhesive polymeric platforms for controlled drug delivery, Eur. J. Pharm. Biopharm. Off. J. Arbeitsgemeinschaft Für Pharm. Verfahrenstechnik EV. 71 (2009) 505-518. doi:10.1016/j.ejpb.2008.09.028.

[36] B.E. Al-Dhubiab, A.B. Nair, R. Kumria, M. Attimarad, S. Harsha, Development and evaluation of buccal films impregnated with selegiline-loaded nanospheres, Drug Deliv. (2014) 1-9. doi:10.3109/10717544.2014.948644.

[37] S. Kanjanabat, T. Pongjanyakul, Preparation and characterization of nicotine-magnesium aluminum silicate complex-loaded sodium alginate matrix tablets for buccal delivery, AAPS PharmSciTech. 12 (2011) 683-692. doi:10.1208/s12249-011-9633-y.

[38] S.Y. Karavana, P. Güneri, G. Ertan, Benzydamine hydrochloride buccal bioadhesive gels designed for oral ulcers: preparation, rheological, textural, mucoadhesive and release properties, Pharm. Dev. Technol. 14 (2009) 623-631. doi:10.3109/10837450902882351.

[39] J. Jacobsen, E.B. Nielsen, K. Brøndum-Nielsen, M.E. Christensen, H.B. Olin, N. Tommerup, M.R. Rassing, Filter-grown TR146 cells as an in vitro model of human buccal epithelial permeability, Eur. J. Oral Sci. 107 (1999) 138-146.

[40] M.E. Jung, W.-J. Kim, Practical syntheses of dyes for difference gel electrophoresis, Bioorg. Med. Chem. 14 (2006) 92-97. doi:10.1016/j.bmc.2005.07.068.

[41] L. Mälkki-Laine, K. Purra, K. Kähkönen, S. Tammilehto, Decomposition of salbutamol in aqueous solutions. II. The effect of buffer species, $\mathrm{pH}$, buffer concentration and antioxidants, Int. J. Pharm. 117 (1995) 189-195. doi:10.1016/0378-5173(94)00329-4.

[42] U.S. Pharmacopeial Convention, ed., USP 36 - NF 31, 36th ed., U.S. Pharmacopeial Convention, Rochville, MD, 2013.

[43] Y. Zhang, M. Huo, J. Zhou, A. Zou, W. Li, C. Yao, S. Xie, DDSolver: an add-in program for modeling and comparison of drug dissolution profiles, AAPS J. 12 (2010) 263-271. doi:10.1208/s12248-010-9185-1.

[44] H.M. Nielsen, M.R. Rassing, TR146 cells grown on filters as a model of human buccal epithelium: III. Permeability enhancement by different $\mathrm{pH}$ values, different osmolality values, and bile salts, Int. J. Pharm. 185 (1999) 215-225.

[45] R.R. Shiledar, A.A. Tagalpallewar, C.R. Kokare, Formulation and in vitro evaluation of xanthan gum-based bilayered mucoadhesive buccal patches of zolmitriptan, Carbohydr. Polym. 101 (2014) 1234-1242. doi:10.1016/j.carbpol.2013.10.072.

[46] S. M. Mazzone, O. Peri, V. Moschetti, Evaluation of Mucoadhesive Properties of Xanthan Gum Hydrogels versus Marketed Ophthalmic Gel Formulations Using a Tensile Strength Method, Invest. Ophthalmol. Vis. Sci. 47 (2006) 1966-1966. http://iovs.arvojournals.org/article.aspx?articleid=2391823 (accessed March 15, 2017).

[47] A.O. Andrade, M.E. Parente, G. Ares, A.O. Andrade, M.E. Parente, G. Ares, Screening of mucoadhesive vaginal gel formulations, Braz. J. Pharm. Sci. 50 (2014) 931-941. doi:10.1590/S1984-82502014000400029.

[48] V.V. Khutoryanskiy, Advances in mucoadhesion and mucoadhesive polymers, Macromol. Biosci. 11 (2011) 748-764. doi:10.1002/mabi.201000388.

[49] R. Imboden, G. Imanidis, Effect of the amphoteric properties of salbutamol on its release rate through a polypropylene control membrane, Eur. J. Pharm. Biopharm. 47 (1999) 161-167. doi:10.1016/S0939-6411(98)00053-8. 
[50] Calculation of molecular properties and bioactivity score, (n.d.).

http://www.molinspiration.com/cgi-bin/properties (accessed September 11, 2014).

[51] N. Zeng, N. Mignet, G. Dumortier, E. Olivier, J. Seguin, M. Maury, D. Scherman, P. Rat, V. Boudy, Poloxamer bioadhesive hydrogel for buccal drug delivery: Cytotoxicity and transepithelial permeability evaluations using TR146 human buccal epithelial cell line, Int. J. Pharm. 495 (2015) 1028-1037. doi:10.1016/j.ijpharm.2015.09.045.

[52] D. Ameye, D. Mus, P. Foreman, J.P. Remon, Spray-dried Amioca starch/Carbopol 974P mixtures as buccal bioadhesive carriers, Int. J. Pharm. 301 (2005) 170-180. doi:10.1016/j.ijpharm.2005.05.016.

[53] R.S. Patel, S.S. Poddar, Development and Characterization of Mucoadhesive Buccal Patches of Salbutamol Sulphate, Curr. Drug Deliv. 6 (2009) 140-144. doi:10.2174/156720109787048177.

[54] S. Pund, A. Joshi, K. Vasu, M. Nivsarkar, C. Shishoo, Gastroretentive delivery of rifampicin: in vitro mucoadhesion and in vivo gamma scintigraphy, Int. J. Pharm. 411 (2011) 106-112. doi:10.1016/j.ijpharm.2011.03.048. 